\title{
DESENVOLVIMENTO HUMANO SUSTENTÁVEL E AS TEORIAS DE JUSTIÇA: ALCANCE E POSSIBILIDADES.
}

\author{
João Paulo Rocha Pereira da Silva* \\ Carlos Augusto Alcântara Machado**
}

RESUMO: O presente artigo busca proporcionar um diálogo entre as teorias de justiça modernas, em particular o utilitarismo de Bentham, o liberalismo de Nozick e a teoria de justiça de Rawls, sob a perspectiva do desenvolvimento sustentável que busca a simetria entre a prosperidade econômica, a inclusão social e sustentabilidade ambiental. Nesse sentindo, questionamos se as teorias de justiça modernas conseguem ser a gramática para alcançar o objetivo proposto pela dimensão do desenvolvimento sustentável? Segue-se o método crítico dialético e a técnica de pesquisa bibliográfica. Nas considerações finais sinaliza-se que as teorias de justiça moderna não se conciliam com sustentabilidade ambiental.

Palavras-Chave: Desenvolvimento humano sustentável. Teoria de justiça. Utilitarismo. Libertarismo. Justiça distributiva.

\section{SUSTAINABLE HUMAN DEVELOPMENT AND THEORIES OF JUSTICE: SCOPE AND POSSIBILITIES.}

ABSTRACT: This paper seeks to provide a dialogue between modern theories of justice, in particular Bentham's utilitarianism, Nozick's liberalism and Rawls' theory of justice, from the perspective of sustainable development that seeks symmetry between economic prosperity, social inclusion and environmental sustainability. In this sense, we question whether modern theories of justice can be the grammar to achieve the goal proposed by the sustainable development dimension? We follow the critical dialectical method and the bibliographical research technique. In the final considerations we signal that modern theories of justice are not reconcilable with environmental sustainability.

Keywords: Sustainable human development. Theory of justice. Utilitarianism. Libertarianism. Distributive justice.

\footnotetext{
* Mestrando em Direitos Humanos da Universidade Tiradentes - Unit, Aracaju, SE, Brasil (Bolsista CAPES), linha de Pesquisa Direitos Humanos, novas Tecnologias e Desenvolvimento Sustentável. Especialista em Direito Constitucional. Endereço: Rua Sgt. Benevides, 515, Bairro Primavera, Arapiraca, Alagoas. E-mail: jprpsilva@ hotmail.com.ORCID: http://orcid.org/0000-0002-1918-0764.

* * Doutor em Direito (Efetividade do Direito) pela Pontifícia Universidade Católica de São Paulo - PUC/SP; Mestre em Direito (Ordem Jurídica Constitucional) pela Universidade Federal do Ceará - UFC. Professor Titular do Mestrado em Direitos Humanos da Universidade Tiradentes - UNIT e Professor-Colaborador do Mestrado em Constitucionalização em Direito da Universidade Federal de Sergipe - UFS. Procurador de Justiça no Ministério Público do Estado de Sergipe - MPSE. Endereço: Av. Barão de Maruim, 277, Aracaju- SE. E-mail: cmachado@infonet.com.br.ORCID: http://orcid.org/0000-0002-2834-9699.
} 


\section{INTRODUÇÃO}

Um novo horizonte surgiu quando o desenvolvimento humano sustentável se tornou agenda da comunidade internacional. O grande objetivo dessa versão do desenvolvimento é reformular as antigas visões da economia, sociedade e meio ambiente, pois o projeto é configurá-los num formato harmônico sedimentando a criação de um novo mundo.

As crises que já se perpetuam na nossa vivência não mais podem ser vistas como algo naturalizado. A intensificação da extrema pobreza, desigualdade, mudanças climáticas, entre outros, fomentaram a humanidade a repensar seu lugar e de suas ações no mundo, no sentido de combinar crescimento econômico e equilíbrio das expressões da desigualdade social. Tal lógica de reflexão encadeia o conceito de desenvolvimento humano sustentável.

Em meados dos anos 1960, a gênese do desenvolvimento humano sustentável pode ser vista nas lutas sociais e por meio destas integraram a agenda política e jurídica das Nações Unidas, norteada por três pilares: economia mundial, ambiente físico e sociedade global.

O desenvolvimento humano sustentável é uma utopia concreta e ao alcance da humanidade, existindo vários caminhos, os quais deverão, obrigatoriamente, passar pelo pensamento ético e pela concepção de justiça de cada sociedade.

Os caminhos éticos e a concepção de justiça é o que define, entre outras coisas, como elaborar e executar as políticas públicas capazes de materializar o desenvolvimento humano sustentável e ao mesmo tempo proporcionar uma boa governança.

As principais teorias de justiça modernas escolhidas, aqui analisadas, como possíveis caminhos são: o utilitarismo de Bentham; a teoria de justiça de Rawls (Liberalismo igualitário); e o libertarismo de Nozick. O impacto que elas causam no debate de justiça, assim como seus posicionamentos opostos, foi à razão de suas escolhas. A partir desses pressupostos, se pergunta: as teorias de justiça modernas conseguem abranger e harmonizar o desenvolvimento humano sustentável?

Pressupõe que as teorias de justiça modernas não conseguem abarcar o desenvolvimento humano sustentável em suas nuances essenciais, no tocante a questão ambiental como elemento qualitativo e constitutivo da sociabilidade.

Este trabalho se estrutura em quatro itens. O primeiro item trata sobre o desenvolvimento humano sustentável, sua história, conceito e objetivos, a partir dos autores Sachs (2017), Anjos Filho (2013) e Sen (2010). O segundo momento trata acerca da teoria 
utilitarista de Bentham, se dedicando a apresentar seus fundamentos, com base em Sen (1999) e Sandel (2017). O terceiro item aborda a obra de Rawls (2016) "Uma teoria de justiça", destacando sua abordagem sobre a construção da sociedade e seus princípios. E no quarto item, tratamos sobre o libertarismo com base na teoria de Nozick (2011).

A elaboração do presente artigo segue o método crítico dialético, cuja técnica de pesquisa predominante é a análise bibliográfica.

\section{ELEMENTOS CONCEITUAIS DO DESENVOLVIMENTO SUSTENTÁVEL}

O termo sustentável, segundo Sachs (2017) pode ter sua ligação com o ecossistema, especificamente com a prática da pesca, a qual era desenvolvida com a sensibilidade de observar a população de peixe disponível na região que a atividade era praticada, visando não causar impacto negativo nessa comunidade.

A concepção de sustentabilidade se associa a concepção de desenvolvimento econômico em 1972, por meio da Conferência das Nações Unidas sobre o Meio Ambiente Humano realizada na cidade de Estocolmo. A consolidação do ideal de desenvolvimento sustentável ganhou a gramática da política internacional e apresentou aos países participantes a dimensão do desafio que a humanidade deveria enfrentar. Furtado apud Anjos Filho (2013, p. 29-30) destaca os perigos ambientais:

[...] chamou a atenção para o caráter predatório da civilização e dos processos irreversíveis de degradação do mundo físico, dentre os quais a elevação da temperatura, afirmando ser ingênuo imaginar que estes problemas seriam solucionados necessariamente mediante o progresso tecnológico, como se a aceleração desse mesmo progresso tecnológico não fosse, ao contrário, um dos agravantes da situação.

Os recursos da terra eram finitos. Não era mais desejado que houvesse um distanciamento entre a ciência econômica e a ética, pois o tipo de processo de crescimento econômico poderia minimizar ou aprofundar a desigualdade (ANJOS FILHO, 2013).

O desenvolvimento econômico passou a compor a esfera da justiça. Grandes debates tomaram conta do cenário internacional, em especial, dividindo-os em dois argumentos: crescimento zero, crescimento em primeiro lugar (ANJOS FILHO, 2013).

Após 10 anos de debates sobre os desafios lançados pela conferencia das Nações Unidas sobre o meio ambiente nasceu o relatório da Comissão Mundial sobre o Meio Ambiente e Desenvolvimento, que também pode ser chamado "o novo futuro comum" de 
1987, o qual consolidou e difundiu o conceito de desenvolvimento sustentável. (ANJOS FILHO, 2013).

O primeiro conceito lançado sobre o desenvolvimento sustentável que possui caráter intergeracional, uma vez que dispõe sobre as necessidades do presente sem comprometer o futuro das próximas gerações (SACHS, 2017).

Ainda sobre o relatório, Anjos Filho (2013, p. 38) destaca que "os objetivos do desenvolvimento econômico e social devem ser definidos em termos de sustentabilidade ambiental em todos os países, sejam eles desenvolvidos ou não". Ou seja, a sociedade e a economia, bem como, sua forma de exploração de recursos, os investimentos realizados, devem ser alinhados no sentido de garantir a governabilidade e também, os avanços tecnológicos. Trata-se de conciliar a qualidade de vida e o desenvolvimento econômico.

Em 1992 ocorreu a Conferência das Nações Unidas sobre o Meio Ambiente e Desenvolvimento, sediada na cidade do Rio de Janeiro. Na ocasião, vários documentos foram ratificados, entre os quais se destaca "A Agenda 21" e a "Declaração do Rio de Janeiro para o Desenvolvimento e o Meio Ambiente". A Conferência reafirmou a Declaração sobre o Meio Ambiente de 1972 e criou 21 princípios do direito ambiental internacional. Para este trabalho cinco princípios merecem maior destaque:

\begin{abstract}
$1^{\circ}$ princípio: Os seres humanos estão no centro das preocupações com o desenvolvimento sustentável. Têm direito a uma vida saudável e produtiva, em harmonia com a natureza;

$4^{\circ}$ princípio: Para alcançar o desenvolvimento sustentável, a proteção ambiental deve constituir parte integrante do processo de desenvolvimento, e não pode ser considerada isoladamente deste;

$5^{\circ}$ princípio: Todos os Estados e todos os indivíduos, como requisito indispensável para o desenvolvimento sustentável, devem cooperar na tarefa essencial de erradicar a pobreza de forma a reduzir as disparidades nos padrões de vida e melhor atender às necessidades da maioria da população do mundo;

$6^{\circ}$ princípio: A situação e necessidades especiais dos países em desenvolvimento, em particular dos países menos desenvolvidos relativo e daqueles ambientalmente mais vulneráveis, devem receber prioridade especial. Ações internacionais no campo do meio ambiente e do desenvolvimento devem, também, atender aos interesses e necessidades de todos os países.

$8^{\circ}$ princípio: Para atingir o desenvolvimento sustentável e mais alta qualidade de vida para todos, os Estados devem reduzir e eliminar padrões insustentáveis de produção e consumo e promover políticas demográficas adequadas ${ }^{1}$.
\end{abstract}

Anjos Filho (2013) compreende que o desenvolvimento sustentável possui natureza de direito humano em razão da sua principal meta, isto é, conciliar a necessidade de superar

\footnotetext{
1 BRASIL (1992). Os referidos princípios foram elaborados no Encontro da Agenda 21 ocorrido no Estado do Rio de janeiro em 1992, com o objetivo de implementar o paradigma do desenvolvimento sustentável em toda atividade humana que produz impacto ambiental.
} 
os problemas presentes sem condenar o futuro, criando meios para que o progresso científico esteja em sintonia com a preservação ambiental.

Em 2002 ocorreu a Cimeira Mundial sobre Desenvolvimento Sustentável das Nações Unidas em Johanesburgo e na oportunidade houve a reformulação do conceito de desenvolvimento sustentável. Além disso, ampliou-se o conceito de justiça internacional para o desenvolvimento holístico, que possui como objetivo também questões econômicas, sociais e ambientais. Em outros termos, o desenvolvimento econômico vinculado com a inclusão social e a sustentabilidade ambiental enquanto partes interdependentes. (SACHS, 2017)

O desenvolvimento sustentável é uma concepção normativa de mundo complexo, pretende criar uma interação harmoniosa entre três sistemas: economia; sociedade; e natureza, mas as promessas de recompensa estão à altura do desafio proposto.

As Nações Unidas criaram objetivos de desenvolvimento sustentável para que os países tivessem um direcionamento nessa jornada, haja vista que, por ser um caminho nunca trilhado é necessário um alinhamento de várias forças para materializar seu ideal. De acordo com Sachs (2017, p.14): "os ODS devem ser a bússola, a estrela polar, para o futuro desenvolvimento do planeta entre 2015 e meados do século”.

As bases para concretização do desenvolvimento sustentável são quatro: prosperidade econômica, inclusão e coesão social, sustentabilidade ambiental e boa governança, esta última possui íntima relação com o objetivo do trabalho e sendo um pouco mais desenvolvida.

A boa governança possui como meta contribuir para que a sociedade possa construir um caminho para prosperidade, pois ela incentiva, a prática da proteção do meio ambiente e o desenvolvimento da infraestrutura de forma equilibrada, combate o crime e salvaguardar os indivíduos favorecendo as potencialidades humana de se concretizar. O princípio da boa governança também pode ser aplicado às empresas, nessa perspectiva Sachs (2017, p.14) afirma que as “[...] multinacionais são muitas vezes os intervenientes mais poderosas. O nosso bem-estar está dependente de estas poderosas empresas cumprirem as lei, respeitarem o ambiente natural e ajudarem as comunidades onde operam, sobretudo para combater a pobreza extrema”.

É imperioso que o setor público e o setor privado atuem em harmonia para construir junto com a comunidade as pontes para diálogos sobre o uso da terra, poluição e politica publica, sempre de forma transparente (SACHS, 2017). 
Sachs (2017, p. 535) indica que boa governança é a

[...] governação tem que ver com as regras de comportamento, especialmente nas organizações. Não diz respeito apenas à nossa politica ou governo, mas aplica-se também às grandes organizações com participações importantes no desenvolvimento sustentável, incluindo as empresas privadas. A boa governação abrange não só o setor público, mas também sobretudo as grandes empresas multinacionais.

Diante da importância e da impossibilidade de definir regras universais sobre como implementar os ODS é que se elaborou determinados princípios que devem ser perseguidos pelo setor público e privado: responsabilidade, transparência e participação. (SACHS, 2017).

Responsabilidade que se traduz em realizar as medidas necessárias para buscar o desenvolvimento sustentável; construir relatórios apresentando os avanços e as dificuldades a serem superadas; transparência - tornar públicas as ações dos governos e empresas para combater "paraísos fiscais" e outras atitudes de moral questionável; participação - abrir a possibilidade de o cidadão contribuir nas tomadas de decisões (devemos ir além do processo eleitoral e abrir verdadeiramente a fala do povo para fortalecer o discurso e deliberações públicas; e no campo privado possibilitar que trabalhadores, fornecedores e consumidores tenham voz nos atos institucionais da empresa e assim superar a condição do poluidorpagador, retomando a responsabilidade de conservar o planeta limpo, mesmo que a lei seja omissa cabe a nós não realizar ações que sejam prejudiciais ao outro ou ao futuro).

Sachs (2017) afirma que o grande compromisso da boa governança é com o desenvolvimento sustentável. Deste modo, os Estados não podem mais se refutar dessa nova responsabilidade para com ela.

Não existe um único caminho a seguir para encontrar o desenvolvimento sustentável, nem uma fórmula mágica. Os princípios e bússolas apresentadas permitem variadas possibilidades para suas aplicações, entretanto, esses caminhos estão ligados às Constituições de seus respectivos países. Apresentar-se-ão, no próximo item, três importantes concepções de teoria de justiça.

\section{NOTAS SOBRE A TEORIA DO UTILITARISMO}

O criador dessa corrente de pensamento foi Jeremy Bentham (1748-1832), filósofo britânico que viveu no final do século XVIII e ainda permanece influente nos dias hodiernos. Em sua filosofia defende que o objetivo da prática política deve ser propiciar a felicidade para o maior número de pessoas. 
O utilitarismo ${ }^{2}$ se constrói a partir da análise das coisas ou formas e a quantificação do seu resultado pela geração de felicidade ou prazer ou, até mesmo, pelo distanciamento do sofrimento. A utilidade é compreendida como um estado psicológico de bem-estar, uma vez que ela foi definida como prazer, felicidade ou satisfação. Sobre o utilitarismo Sandel (2017, p.48) afirma que "o mais elevado objetivo da moral é maximizar a felicidade, assegurando a hegemonia do prazer sobre a dor. [...] a coisa certa a fazer é aquela que maximizará a utilidade".

O utilitarismo pode ser aplicado tanto na formulação legislativa de um Estado, como na aplicação de políticas públicas já que seu criador acredita que o homem é governado pela dualidade dos sentimentos dor e prazer, os quais guiam as ações dos seres humanos de tal forma que o julgamento do certo e do errado é definido por eles. Sandel aponta que (2017, p. 48):

A filosofia utilitarista reconhece esse fato e faz dele a base da vida moral e política.
Maximizar a "utilidade" é um princípio não apenas para o cidadão comum, mas
também para os legisladores. Ao determinar as leis ou diretrizes a serem seguidas,
um governo deve fazer o possível para maximizar a felicidade da comunidade em
geral.

Para Bentham apud Sandel (2017) todos os argumentos morais devem ser elaborados a partir dessa concepção de máxima felicidade, de tal forma que ele o aplicou no âmbito do direito penal - especificamente no sistema penitenciário; criando o panópticon ${ }^{3}$.

O utilitarismo propõe três meios para a realização de sua prática: a) o consequencialismo - preconiza que as ações tomadas devem ser analisadas pelo resultado por elas provocadas; b) o welfarismo - limita a avaliação do objeto a sua utilidade ${ }^{4}$; c) a terceira é o ranking pela soma - dita que a soma da utilidade deve ser maximizada sem levar em consideração o grau de desigualdade na distribuição das utilidades.

Essa quantificação para alcançar a felicidade ocorre sem julgamento das preferências. A torna atrativa, especialmente para as ciências econômicas, já que para o utilitarista a injustiça seria ter um agregado de utilidade menor do que se poderia alcançar.

\footnotetext{
${ }^{2}$ Segundo o dicionário do pensamento do século XX: utilitarismo é a tradição em teoria moral, política e social que avalia a retidão dos atos, escolha, decisões e políticas por sua consequência em relação ao bem-estar humano (FREY, 2011, p. 785).

${ }^{3}$ Sandel (2017, p. 49) trata esse conceito como "Um presídio com uma torre central de inspeção que permitisse ao supervisor observar os detentos sem que eles o vissem".

${ }^{4}$ Para Sen (2010, p. 85) “[...] quando o welfarismo é combinado ao consequencialismo, temos o requisito de que toda escolha deve ser julgada em conformidade com as respectivas utilidades que ela gera".
} 
Sen (2010) destaca três críticas sobre o utilitarismo: a) a falta de sensibilidade para as questões distributivas, posto que, a desigualdade na distribuição do prazer não entra no cálculo; b) pouca relevância dada aos aspectos de direitos e liberdades; c) a fragilidade do conceito de bem-estar que pode gerar resultados nocivos caso seja utilizado como manipulação para o convencimento da população sobre determinada deliberação.

A incapacidade do utilitarismo de garantir direitos individuais a partir da soma de felicidade da maioria. Ressalta-se que, tal processo não deixa espaço para o respeito da vontade do indivíduo. Nessa perspectiva, o indivíduo só possui importância durante o processo somatório das vontades para alcançar a dita felicidade, entretanto, a partir do momento que ele se enquadra no lado "opositor", sua manifestação de vontade pela felicidade não tem espaço na sociedade.

Conforme Sen (1999, p. 61), o bem-estar no utilitarismo

Julgar o bem-estar de uma pessoa exclusivamente pela métrica da felicidade ou
satisfação de desejos tem algumas limitações óbvias. Essas limitações são
particularmente prejudiciais no contexto das comparações interpessoais de bem-
estar, pois o grau de felicidade reflete o que uma pessoa pode esperar e como o
"trato" social se afigura em comparação com essa expectativa. [...] A métrica da
felicidade pode, portanto, distorcer o grau de privação, de um modo específico e
tendencioso.

Dessa forma, depreende que o problema específico da influência das circunstâncias contingentes sobre a métrica da utilidade é apenas o reflexo de um problema mais básico: a insuficiente profundidade do critério de felicidade para alcançar o bem-estar da pessoa.

O utilitarismo se pauta de uma quantificação para se alcançar a felicidade e os perigos desta modalidade para alcançar o desenvolvimento humano sustentável pode ser percebido no exemplo trazido por Sandel (2017, p. 59) sobre como a lógica utilitarista trabalha num caso prático de proteção ambiental.

Em 2003, a EPA ${ }^{5}$ apresentou uma análise de custo e benefício dos novos padrões de poluição do ar. A agência atribui um valor mais generoso á vida humana do que a Ford, porém com uma diferença no ajuste de idade: 3,7 milhões de dólares por vida salva em consequência do ar mais puro, exceto para aqueles acima de 70 anos, cujas vidas foram avaliadas em 2,3 milhões. Por trás das diferentes avaliações havia um princípio utilitarista: salvar a vida de uma pessoa mais idosa é menos útil do que salvar a vida de uma mais jovem. (O jovem tem mais vida pela frente e, portanto, mais felicidade para usufruir.) Defensores dos mais idosos não raciocinavam assim. Eles protestaram contra "desconto para cidadão idoso", argumentando que o governo não deveria atribuir um valor mais alto à vida dos jovens do que á dos idosos. Abalada pelo protesto, a EPA rapidamente desistiu do desconto e tirou o relatório de circulação.

\footnotetext{
${ }^{5}$ Agência de Proteção Ambiental dos Estados Unidos da América.
} 
A máxima do utilitarismo pode levar a monetização da vida, do meio ambiente e dos valores morais; além de fragilizar o senso de bem comum e a empatia entre os indivíduos. É temeroso considerar todos os valores como algo mensurável e construir uma escala de comparação entre eles, pois questões ecológicas irão estar sempre ameaçadas pelo discurso do crescimento econômico como a máxima felicidade. Nessa linha, explica Gargarella (2008, p.11) " [...] o utilitarismo vem a ser perfeitamente compatível com a produção de certas violações de direitos (os direitos de uma minoria), em nome do bem-estar geral - em nome do bem estar majoritário."

Esse espírito acrítico do utilitarismo não é desprovido de uma ideologia, como ensina Tugendhat (2012, p. 327) “[...] o utilitarismo é a ideologia do capitalismo, pois ele permite o crescimento da economia como tal, sem dar moralmente conta daquilo que diz respeito a questões de partilha", ou seja, se esconde a ideologia capitalista do utilitarismo para permitir que continue atrativo mesmo com o espírito acrítico.

\section{A TEORIA DE JUSTIÇA DE JOHN RAWLS}

A obra do filósofo John Rawls (2016) "Uma teoria de justiça" de 1971, tem como objetivo superar o pensamento utilitarista ou em suas palavras Rawls (2016, p.3) “[...] é elaborar uma teoria da justiça que seja uma alternativa viável a essa doutrinas que há muito dominam nossa tradição filosófica." por meio do resgate das teorias contratualistas ${ }^{6}$, propondo que não é possível alcançar a justiça sem moral política ou econômica.

Rawls (2016, p.6) questiona sobre o justo e o injusto das instituições, a partir do argumento "pode-se imaginar a concepção pública da justiça como aquilo que constitui a carta fundamental de uma associação humana bem-ordenada". Essa premissa se distancia da questão do justo numa perspectiva individual para buscar um justo de interesse comum. Entende-se que justiça deve ser meio e fim para as instituições sociais, as quais, de acordo

\footnotetext{
${ }^{6}$ Gargarella (2008, p.18) explica a importância do contrato na teoria de Rawls como: "O contrato em questão, em suma, serve para moldarmos a ideia de que nenhuma pessoa está, de modo inerente, subordinada ás demais. Esse contrato hipotético, então, vem negar, e não refletir - como parece ocorrer nos contratos hobbesianos -, nossa desigual capacidade de negociação. Portanto, o contratualismo hobbesiano e o rawlsiano surgem comprometidos com uma ideia diferente de igualdade: a igualdade que interessa a Rawls não tem a ver com igual poder físico (capaz de nos forçar a firmar um contrato mutuamente benéfico), mas como nosso igual status moral, que nos força, em todo caso, a desenvolver uma preocupação com imparcialidade - pelo fato de se considerarem imparcialmente as preferências e interesse de cada um".
} 
com suas concepções públicas, precisam cumprir com zelo as normas que a constituem adequando as estruturas básicas da sociedade para alcançar a justiça social ${ }^{7}$.

O que define justiça social é a forma como essas instituições sociais vão distribuir os direitos e deveres fundamentais, assim como a maneira como vão dividir os benefícios da cooperação social. Para tanto, se concebe uma reabertura de distribuição almejando alcançar as questões de justiça social, oportunidades econômicas e as condições sociais de forma ampla para todos os seguimentos sociais.

Rawls (2016) reconstrói a teoria do contrato social como uma ferramenta argumentativa e hipotética com o intuito de destacar uma posição original que vai evidenciar a necessidade da igualdade entre os pares para a concepção dos direitos e deveres.

O uso do contrato social traduz a necessidade de se ter um ponto de partida capaz de colaborar com sua visão sobre o papel da economia na sua teoria. Ao analisar o pensamento do filósofo norte americano Sandel (2017, p. 190) destaca "Sua ideia principal é que a distribuição de renda e oportunidade, não deve ser fundamentada em fatores arbitrários do ponto de vista moral.” Dessa forma, Rawls (2016), hipoteticamente, refunda a sociedade onde todos os pactuantes se encontram de forma igual, o que o autor vai chamar de posição original, explica Rawls (2016, p. 146).

A posição original é definida de modo a ser um status quo no qual todos os acordos
firmados são justos. É uma situação na qual as partes são igualmente representadas
como pessoas morais, e o resultado não é condicionado por contingências arbitrárias
nem pelo equilíbrio relativo das forças sócias. Assim, a justiça como equidade pode
usar a ideia de justiça procedimental pura desde o início.

De acordo com Rouanet (2009) esse processo que ocorre durante a posição original se faz através do véu da ignorância, um artifício criado para que os indivíduos ignorando sua situação na sociedade atual e suas possibilidades futuras decidam esses princípios deixando de lado seus interesses próprios dosados pela imprecisão de suas chances. A ideia da posição original é possibilitar que a construção dos direitos e deveres pelos cidadãos que compõem determinada sociedade seja realizada de forma mais igualitária, quer em condições, quer em oportunidade.

Rawls (2016, p.73) apresenta dois princípios fundamentais de sua teoria: o princípio da igualdade e o princípio da diferença. Estes princípios vão sedimentar a atuação das instituições sociais

\footnotetext{
${ }^{7}$ Segundo Lima (2019), Rawls defende que somente a justiça social assegura a igualdade de oportunidade aos indivíduos, deixando-os em um patamar de liberdade igual capaz de favorecer a cooperação social.
} 
A primeira formulação dos dois princípios é a seguinte: Primeiro: cada pessoa deve ter um direito igual ao sistema mais extenso de iguais liberdades fundamentais que seja compatível com um sistema similar de liberdades para as outras pessoas. Segundo: as desigualdades sociais e econômicas devem estar dispostas de tal modo que tanto (a) se possa razoavelmente esperar que se estabeleçam em benefício de todos com (b) estejam vinculadas a cargos e posições acessíveis a todos.

É recorrendo ao primeiro princípio que Rawls (2016) apresenta sua compreensão de liberdade e o segundo princípio revela a forma de execução dessa liberdade que prevê minimizar a desigualdade. Rawls (2016, p.127) ao criar uma correlação com o lema da Revolução Francesa de 1789-1799 (Liberdade, Igualdade e Fraternidade), define a atuação dos princípios retro mencionados com o princípio da fraternidade em sua concepção de justiça social como: "a liberdade corresponde ao primeiro princípio; a igualdade, à ideia de igualdade contida no primeiro princípio juntamente com a igualdade equitativa de oportunidades; e a fraternidade ao princípio de diferença".

A liberdade básica, discutida por Rawls (2016) é definida pela liberdade política - que se entende como a participação no jogo democrático e ocupação de funções públicas; a liberdade de consciência e pensamento; a liberdade da pessoa - integridade física; a liberdade de expressão e reunião; a proteção de prisão arbitrária; e a propriedade privada (JESUS, 2011).

Já o segundo princípio é interpretado em sintonia com a igualdade democrática para que possa conceber uma distribuição de riqueza concreta para usufruir dos benefícios sociais.

Essa construção é dividida em três etapas que partem das questões mais abstratas para as mais concretas realizadas pelos pactuantes da seguinte forma: a) na primeira se elenca os princípios; b) na segunda se elabora a Constituição; c) na terceira se elabora formas de aplicação das políticas de bem estar da sociedade, possibilitando justiça social, mas observando os aspectos econômicos. (RAWLS, 2016)

Não se procura eliminar a desigualdade ou criar um novo debate sobre a distribuição natural, se procura elaborar uma teoria que faça com que as instituições possuam atribuições de justiça minimizando as questões de exclusão social proporcionada pela questão econômica. A teoria de Rawls (2016) garante maior abertura de oportunidades e fomenta uma estrutura cooperativa entre os entes da sociedade.

$\mathrm{O}$ autor procura atribuir um caráter objetivo ao justo, independente da vontade de grupos políticos detentores de poder que possa servir de interpretação dos princípios positivados nas Constituições. (LIMA, 2019) 
Para Sandel (2017) os princípios definidos por Rawls (2016) pretendem superar o debate sobre a utilidade social e o bem-estar geral traçando uma equidade social e econômica que favorece os excluídos e salvaguarda a renda e a riqueza individual.

Rawls (2016) amplia a concepção de justiça abarcando a atuação do Estado e outras instituições para alcançar o justo. Esta perspectiva está parcialmente em sintonia com os objetivos do desenvolvimento humano sustentável. Pode-se de acordo com Rawls (2016, p. 122),

[...] podemos rejeitar o argumento de que a organização das instituições é sempre deficiente, porque a distribuição dos talentos naturais e as contingências das circunstancias sociais são injustas, e essa injustiça deve, inevitavelmente, transportar-se às instituições humanas. De tempo em tempo essas ponderações é apresentada como desculpa para ignorar a injustiça, como se recusar-se a aquiescer à injustiça fosse o mesmo que a incapacidade de aceitar a morte. A distribuição natural não é justa nem injusta; nem é justo que se nasça em determinada posição social. Isso são meros fatos naturais. Justo ou injusto é o modo como às instituições lidam com esses fatos.

Rawls (2016, p. 122) prossegue:

O sistema social não é uma ordem imutável inacessível ao controle humano, porém um padrão de atividades humanas. Na justiça com equidade, os homens concordam em só se valer dos acidentes da natureza e das circunstâncias sócias quando fazê-lo resulta em benefício comum. Os dois princípios são um modo equitativo de enfrentar a arbitrariedade da sorte; e, por mais imperfeitas que possam ser em outros aspectos, as instituições que atendem a esses princípios são justas.

O reconhecimento da teoria de Rawls (2016) para o debate político é medido pelo impacto que sua obra obteve e os longos debates que realizou com grandes teóricos de sua época, possibilitando ajustes posteriores durante toda a sua vida. Entretanto, quando é relacionada com o desenvolvimento sustentável compreende-se que a questão ambiental não é comtemplada em todas as suas dimensões.

\section{IDEOLOGIA LIBERTÁRIA: CONCEITOS E CARACTERÍSTICAS}

Os libertários propõem a defesa do mercado livre e qualquer forma de regulamentação do governo sob a bandeira da eficiência econômica e em defesa do direito sagrado da liberdade humana. Todos os homens são livres e gozam do direito de fazer o que quiserem com aquilo que os pertence, desde que seja respeitado o mesmo direito para o outro.

Dentro dessa corrente filosófica o Estado possui um rol taxativo e inflexível de atribuições que são: a) fazer cumprir os contratos firmados pelas partes, de forma livre e em 
consonância com a Lei; b) garantir a segurança e a paz dos cidadãos; c) proteger a propriedade privada.

O libertarismo também rejeita qualquer forma de paternalismo de qualquer natureza, pois vê como uma interferência do Estado na vida privada, mesmo que esta seja para proteger o indivíduo de si mesmo. As legislações sobre temáticas morais também são rejeitadas, pois não cabe ao Estado se utilizar da força institucionalizada para intervir na opinião dos indivíduos e nas suas concepções de virtude e justiça, e, por fim de nenhuma redistribuição de renda. O Estado não pode interferir nos ganhos do indivíduo para ajudar outro porque seria uma forma de violação do Estado instituir impostos que tenham como objetivo a distribuição de riquezas com o intuito de auxiliar os menos favorecidos em qualquer modalidade (saúde, educação, alimentação, cultura etc.).

A teoria libertária surgiu como oposição ao Estado de bem-estar social na década de 1960. Dois destacados pensadores criaram a base teórica da corrente filosófica: Friedrich A. Hayek (1899-1992); e Milton Friedman (1912-2016). Para Hayek apud Sandel (2017) qualquer ação que busque maior igualdade econômica destruiria uma sociedade livre e para Friedman boa parte das atribuições estatais são violações da liberdade individual, ele vai se opor a regulamentação do salário mínimo; a proteção da discriminação do trabalho; a regulamentação de atividade profissional; tudo sob o argumento de que o mercado regula a atuação e a escolha dos indivíduos (SANDEL, 2017).

Nozick (2011) é um expoente da ideologia libertária que elabora sua teoria na obra “Anarquia, Estado e Utopia” elaborada em 1974 como resposta á obra de John Rawls. A concepção de Estado para Nozick, (2011, IX) indica que

[...] o Estado são que um Estado mínimo, que se restrinja às estritas funções de
proteção contra a violência, o roubo, a fraude, a coação de contratos, e assim por
diante, é justificado; que qualquer Estado mais abrangente violará os direitos de as
pessoas não serem obrigadas a fazer determinadas coisas, o que não se justifica; e
que o Estado mínimo é ao mesmo tempo inspirador e justo. Duas implicações dignas
de nota são que o Estado não pode usar seu aparelho para obrigar alguns cidadãos a
ajudar outro ou para proibir a prática de atividades que as pessoas desejarem realizar
para o seu próprio bem ou proteção.

A percepção de Nozick (2011) sobre o Estado tem por meta garantir a individualidade restringindo o senso de bem comum e conservar o status quo da posição social ao dificultar as oportunidades dos menos favorecidos alcançarem situação melhor. Para Nozick (2011), a única forma de justiça distributiva seria referente à aquisição histórica da posse pela 
dificuldade de se garantir a legitimidade da aquisição pelos antepassados, e, mesmo assim, não tem caráter de redistribuição de riqueza.

Nozick (2011, p. 193) apresenta três fundamentos para explicar a propriedade

1. A pessoa que adquire um bem de acordo com o princípio de justiça na aquisição tem direito a esse bem. 2. A pessoa que adquire um bem, de acordo com o princípio de justiça na transferência, de outra pessoa que tem direito ao bem, tem direito a ele. 3. Ninguém tem o direito a um bem exceto por meio da aplicação (repetidas) de 1 e 2.

Segundo o filósofo libertário qualquer aquisição de forma ilegítima invalida a aquisição da posse, permitindo que o Estado venha agir para suprimir. A liberdade é o maior dos direitos e a justiça distributiva limita esse direito sob o argumento da desigualdade econômica, mas, na verdade, ela camufla a razão de a desigualdade econômica se resultado as escolhas dos indivíduos, com explica o autor. Nesse sentido, tributar fundamentando na minimização da desigualdade se equivale ao trabalho forçado, pois, como leciona Nozick (2011, p.217) “[...] apropriar-se do pagamento de $n$ horas de trabalho é como apropriar-se de $n$ horas da pessoa; é como obrigar a pessoa a trabalhar $n$ horas em prol dos objetivos de outrem”. Nozick (2011) Acrescenta que ao retirar o lucro do trabalho de alguém é igual a possuir o seu tempo de trabalho, o que torna o indivíduo parcialmente propriedade do Estado.

Sandel (2017, p.84-85) sinaliza que

[...] a ideia de que uma pessoa é a única proprietária de si mesmo. Se sou senhor de mim mesmo, devo ser senhor do meu trabalho. (Se outro individuo pudesse me obrigar a trabalhar, esse indivíduo seria meu senhor e eu seria seu escravo.) Mas, se sou dono do meu trabalho, devo ter direito aos seus frutos. (Se outra pessoa tiver o direito aos meus rendimentos, essa pessoa será dona do meu trabalho e será, consequentemente, minha dona.)

Importante salientar que não existe qualquer impedimento contra a realização espontânea de auxílio às pessoas em dificuldade econômica nessa teoria. O que não é admissível é a tributação obrigatória, mesmo que seja, fruto de deliberação legislativa pelos representantes do povo. O libertarismo, em sua defesa extrema das liberdades individuais, concebe um ser individualista e utópico que rompe com o senso comum e com os conceitos de fraternidade, comunidade e democracia, sedimentando uma sociedade de indiferentes.

Para Sen (2010) o libertarismo é limitado por negligenciar as liberdades substantivas ${ }^{8}$ pela sua inflexibilidade em defesa de um individualismo que é o grande cerne moral da teoria.

\footnotetext{
${ }^{8}$ Sen (2010) conceitua liberdade substantiva, os direitos individuais, liberdades processuais (que é o processo para garantir as liberdades), a liberdade de educação, política e de expressão, além de evitar a fome crônica.
} 
Rouanet (2009) descreve a obra "Anarquia, Estado e Utopia" como um paradoxo, pois com seu estilo leve e bem humorado exercita o direito de oposição às ideias de Rawls (2016). Contudo, "de forma ultralockeana", chegando às últimas consequências (pouco convincente e antidemocrática).

Sandel (2005, p. 99- 100) nota similaridades mesmo em teorias antagônicas como a de Rawls (2016) e Nozick (2011), em razão de possuírem a mesma base filosófica sobre o liberalismo:

\begin{abstract}
A partir de um ponto de vista político prático, as posições de Rawls e de Nozick opõem-se com clareza. Rawls, o liberal, defensor do Estado de bem-estar, e Nozick, o conservador libertário, definem entre si as alternativas mais claras que a agenda política norte-americana tem para oferecer, pelo menos naquilo que à justiça distributiva diz respeito. E, no entanto, a partir de um ponto de vista filosófico, têm muito em comum. Um e outro definem as suas posições em oposição explícita ao utilitarismo, que ambos rejeitam com o fundamento de este negar a distinção entre pessoas. Ambos oferecem, em alternativa, uma ética baseada em direitos, proposta com vista a assegurar de forma mais completa a liberdade dos indivíduos. [...] Ambos negam que exista qualquer entidade social acima ou para além dos indivíduos que a compõem.
\end{abstract}

Continua Sandel (2005, p. 101):

Rawls chega a uma teoria da justiça no quadro da qual se aceitam desigualdades económicas e sociais apenas na medida em que beneficiem os mais desfavorecidos, enquanto que, para Nozick, a justiça se situa unicamente nas trocas e nas transferências voluntárias, o que exclui todas e quaisquer políticas redistributivas.

As teorias ditas libertárias podem favorecer ao desenvolvimento econômico, porém são incapazes de propiciar inclusão social e questões ambientais, tornando-as incompatíveis com a era do desenvolvimento humano sustentável.

\title{
6 CONCLUSÃO
}

O Desenvolvimento Humano Sustentável se funda em quatro pilares básicos: desenvolvimento econômico; inclusão social; sustentabilidade e boa governança. Este último sempre em conflito ou é pouco explorado nas teorias de justiça modernas.

O utilitarismo não consegue se relacionar com a boa governança, pois sua busca pela felicidade é incompatível com a forma responsável e transparente de governar, além de não permitir espaço para a sustentabilidade ou inclusão social.

O liberalismo em sua amplíssima defesa do indivíduo, não tem responsabilidade para com o outro, de forma que a natureza não é aceita como um novo jogador no debate político. 
A teoria de Rawls (2016) apresenta plena sintonia com três dos quatro pilares: desenvolvimento econômico; inclusão social e boa governança, mas não com a sustentabilidade. Rawls não concebe uma perspectiva para além do homem. O contrato social é feito por homens, para homens e a natureza não é contemplada, posto que não é vista como um dos bens primários, além de não estar contemplada nos dois princípios defendidos na teoria.

As teorias de justiça modernas possuem como centro de suas análises o indivíduo, de forma exacerbada, não permitindo um novo "agente" que venha dividir o protagonismo, uma vez que, o utilitarismo e libertarismo são opostos à ideologia do desenvolvimento humano sustentável. No entanto, ressalte-se que as contribuições de Rawls (2016) podem somar com o desenvolvimento humano sustentável. Entende-se que a compreensão dos limites para a proposta do desenvolvimento humano sustentável, pode significar uma contribuição parcial na direção da nova teoria de justiça que esteja em sintonia com a nova era.

\section{REFERÊNCIAS}

ANJOS FILHO, Robério Nunes dos. Direito ao desenvolvimento. São Paulo: Saraiva, 2013.

BRASIL. Declaração do Rio de Janeiro. Disponível em:: https://www.scielo.br/pdf/ea/v6n15/v6n15a13.pdf. Acesso em: 17dez 2020.

FREY, R. G. Verbete - Utilitarismo - IN OUTHWAITE, William; BOTTOMORE, Tom. Dicionário do Pensamento Social do século XX. Rio de Janeiro: Zahar, 1996.

GARGARELlA, Roberto. As teorias da justiça depois de Rawls: um breve manual de filosofia política. São Paulo: WMF Martins Fontes, 2008.

JESUS, Carlos Frederico Ramos de. John Rawls: a concepção do ser humano e a fundamentação dos direitos do homem. Curitiba: Juruá, 2011.

LIMA, Newton de Oliveira. Dez lições sobre Rawls. Petrópolis/RJ: Vozes, 2019.

NOZICK, Robert. Anarquia, estado e utopia. São Paulo: WMF Martins Fontes, 2011.

RAWLS, John. Uma teoria de justiça. São Paulo: Martins Fontes, 2016.

ROUANET, Luiz Paulo. Rawls. IN PECORARO, Rossano. Os filósofos: clássicos da filosofia: V. III: de Ortega y Gasset a Vanttimo. Petrópolis/RJ: Vozes, 2009.

SACHS, Jeffrey D. A era do desenvolvimento sustentável. Lisboa: Conjuntura actual editora, 2017. 
SANDEL, Michael J. O liberalismo e os limites da justiça. Lisboa: Fundação Calouste Gulbenkian, 2005.

. Justiça - o que é fazer a coisa certa. Rio de Janeiro: Civilização brasileira, 2017.

SEN, Amartya. Desenvolvimento com liberdade. São Paulo. Companhia das letras, 2010. . Sobre ética e economia. São Paulo. Companhia das letras, 1999.

TUGENDHAT, Ernst. Lições sobre ética. Petrópolis/RJ: Vozes, 2012. 